Bangladesh Journal of Anatomy January 2011, Vol. 9 No. 1 pp 30-34

\title{
High Waist to Hip Ratio as a Risk Factor for Ischemic Stroke Patients Admitted in a Tertiary Care Hospital
}

\author{
Md Habib Khan ${ }^{1}$, Sanjoy Kumar Chakraborty², Rajat Sanker Roy Biswas ${ }^{3}$
}

\begin{abstract}
Context: Stroke is a problem now days. The purpose of this study is to see the association of high waistto-hip ratio with ischemic stroke and also to see the correlation with other risk factors of ischemic stroke.

Study type: Hospital based cross sectional descriptive study

Methods: It is a study conducted on purposively selected (non probability) hospitalized patients who had been admitted into neuromedicine ward of Chittagong Medical College Hospital (CMCH), Chittagong prooved during a period of 6 months extending from $1^{\text {st }}$ January 2009 to $31^{\text {st }}$ June 2009. 50 cases with CT scan prooved ischemic stroke of brain were interviewed and examined and had measurements of waist and hip circumference and waist to hip ratio (WHR) were calculated.

Results: $64 \%$ of the ischemic stroke patient had abnormal WHR. The correlation with other risk factors showed that $90 \%$ of ischemic stroke patient had other co-morbidity. Among them $76 \%$ patient had hypertension, 38\% patients had history of smoking, $16 \%$ patients had diabetes mellitus and $12 \%$ patients had dyslipidaemia.
\end{abstract}

Conclusion: The results reveal that high waist to hip ratio might have an association with ischemic stroke.

Key words: Ischemic stroke, Waist-to-Hip Ratio (WHR).

Introduction:

The prevalence of overweight or obese peoples is rapidly increasing worldwide ${ }^{1}$. The impact of obesity on public health is a growing concern because obesity is well recognized to be related to many diseases such as Type 2 diabetes mellitus, hypertension, dyslipidaemia, sleep apnoea and stroke ${ }^{2}$. The unfavorable effect of obesity on coronary heart disease and overall mortality is well recognized ${ }^{3}$. The relationship between obesity and ischemic stroke however remain less clear.

Stroke is a global health problem. It is the leading cause of adult disability and the second leading cause of mortality worldwide (world Health Report, 2003). It is a leading cause of functional impairment,

1. Associate Professor of Anatomy, BGC Trust Medical College, Chittagong.

2. Assistant Professor of Anatomy, BGC Trust Medical College, Chittagong

3. Thesis part student of MD (Internal Medicine)Chittagong Medical College

Correspondence: Md. Habib Khan with $20 \%$ of survivors requiring institutional care after three months and 15\%-30\% being permanently disabled ${ }^{1}$. Compared with the volume of prospective studies in coronary heart disease, there have been relatively fewer population studies investigating the risk of stroke. Current treatments for patients with established stroke are relatively less effective and risk factor interventions are the real hope of reducing stroke morbidity and mortality in populations ${ }^{2,3}$.

Few studies have examined the relationship between abdominal obesity defined by WHR and stroke. Swedish investigators suggested that increased WHR may be a risk factor for stroke in women ${ }^{4}$ and men $^{5}$ but these results were limited by small number of cases. The Northern Manhattan stroke study group suggested that abdominal obesity is an independent, potent risk factor for ischemic stroke in all race and ethnic groups ${ }^{2,3}$. The health professionals' follow-up study showed that the highest level of WHR was associated with an increased risk of stroke among men but did not ascertain the effect of hypertension, diabetes 
mellitus and high cholesterol on stroke ${ }^{4}$. Therefore, the information about abdominal obesity as a risk factor for ischemic stroke is very limited, and to date, there has been no study in Bangladesh.

There are different anthropometric measurements for identifying obesity. Waist to hip ratio is an important and comparatively easy tool to identify obesity in stroke patients. The prevalence of stroke in our country is increasing day by day. There are few studies to evaluate risk factors of ischemic stroke but no adequate study on association of abdominal obesity in terms of waist to hip ratio with ischemic stroke. Stroke is a preventable disease by early notification of risk factors. So this study will help for better understanding of risk factors and stroke prevention.

\section{Materials and method:}

The study was carried out on 50 ischemic stroke patients. The study was done from January 2009 to June 2009. All the samples were collected from the neuromedicine wards of $\mathrm{CMCH}$. Adult patients of stroke ischemic in type as evidenced by CT scan were included in the study and patients with hemorrhagic stroke were excluded. Patients with abdominal lump, ascites and skeletal deformity of hip and spine were also excluded from the study.

\section{Research instruments:}

a. Structured questionnaire.

b. Flexible measuring tape.

Data collection procedure: Data were collected from the patients who were admitted to the neuromedicine ward of $\mathrm{CMCH}$. Detailed history was collected in structured questionnaire which includes name, age, sex, occupation, religion, monthly income, academic qualifications and co-morbidity. The form also contains different physical signs found on examination ranging from general examination to systemic examinations.

As this study renders primary importance to ischemic stroke, waist to hip ratio and other comorbidity were recorded. Waist circumference was measured at a level midway between the lower rib margin and iliac crest with the tape all around the body in horizontal position. Hip circumference was measured as the maximal circumference over the buttocks in horizontal position.
Data Processing, analysis and interpretation: After compilation of data, the obtained data were checked, verified, edited and coded. The data were analyzed and statistical evaluation was performed by SPSS version 15.0 (Chicago, Illinois, USA) program.

Ethical approval: This study was approved by ethical review committee of Chittagong Medical College.

\section{Results:}

The anthropometric measurement concerned here with this study was waist to hip ratio (WHR). For purpose of waist to hip (WHR) ratio calculation, waist circumference and hip circumference were recorded. WHR was calculated for each patient the result of which shows that $32(64 \%)$ patients had abnormal WHR( $>1$ in men and $>0.85$ in women) while 18 (36\%) patients had been found to possess normal WHR. Of the 35 male, 22(62\%) had abnormal ratio (>1) and $13(38 \%)$ were normal and of 15 female $10(66 \%)$ had abnormal (>0.85) and rest 5(34\%) had normal WHR. The results are shown in Table - I, II, Figure1, 2, 3.

Table-I

Age distribution among the stroke patients

\begin{tabular}{lcc}
\hline Age in years & Total number $(\mathrm{n})$ & Percent $(\%)$ \\
\hline$>60$ & 25 & 50 \\
$50-59$ & 16 & 32 \\
$40-49$ & 6 & 12 \\
$30-39$ & 2 & 4 \\
$20-29$ & 1 & 2 \\
\hline
\end{tabular}

Table-II

Nature of occupation among the stroke patients

\begin{tabular}{lcc}
\hline Occupation & Total number (n) & Percent (\%) \\
\hline Farmer & 11 & 22 \\
House wife & 12 & 24 \\
Service holder & 14 & 28 \\
Traders & 6 & 12 \\
Retired person & 5 & 10 \\
Day laborer & 2 & 4 \\
\hline
\end{tabular}




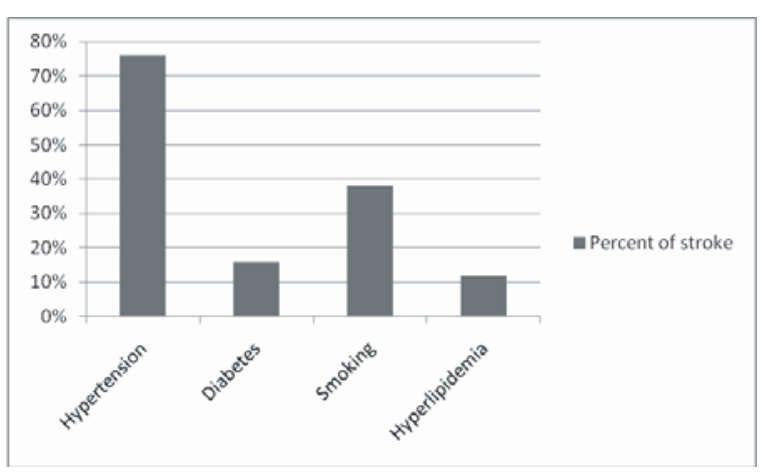

Fig.- 1: Bar diagram showing the percentages of stroke in various risk factors

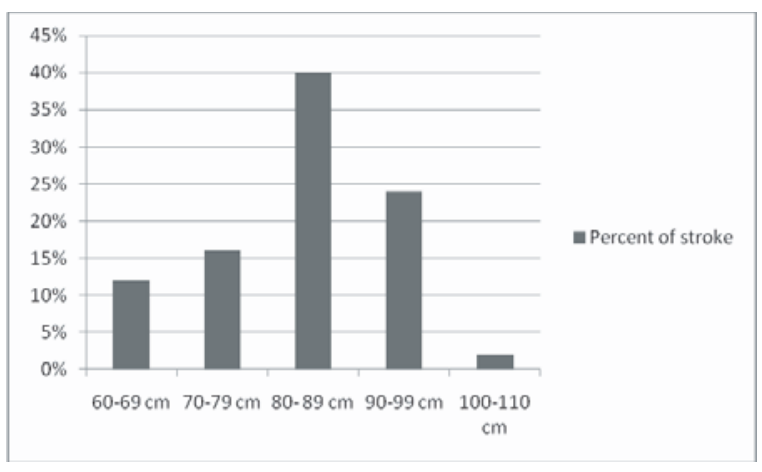

Fig-2: Bar diagram showing the percentages of stroke in relation with different waist circumference.

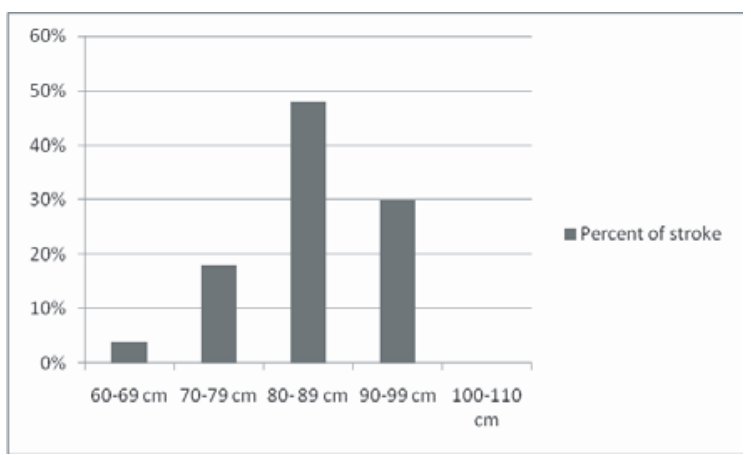

Fig.- 3: Bar diagram showing percentage of stroke in relation with different hip circumference.

\section{Discussion:}

In the present study a definite association was found between obesity as measured by WHR and incidence of ischemic stroke(64\%). The strength of the association between WHR and ischemic stroke in our study was as great as that observed for definite hypertension, smoking, diabetes mellitus and hyperlipidaemia. The study population show that $70 \%$ patients were male and $30 \%$ patients were female. Clinical presentation of the study population varied in patient to patient. Major risk factors among these patients were identified and co-related. Majority of the patients in this study were of age 50 years and above (82\%) and peak age incidence was above 60 years group (52\%). Only $18 \%$ of the patient were under 50 years and no case was found at or below age twenty years. In this study the frequency of stroke increases with increasing age that corelates with the result of similar studies in home and abroad $^{6}$. In this study stroke affected males were 2.3 times more common than female and the ratio being 2.3:1 which co-relates with other studies. ${ }^{6}$ but a similar study by Mannan \& Alamgir ${ }^{7}$ showed significant difference (M:F=4:1). The male female ratio is higher in our country than that of western countries. This preponderance of male may be due to the cultural attitude of our society, that the female are not generally brought to the hospital, particularly the tertiary level hospital. But in this study, the ratio has come down to a reasonable level, which reflect indirectly on improvement of the cultural attitude and as well as health consciousness in our society.

The occupational basis of this study shows, mostly affected patients were service holders (28\%), next majority were house wives (24\%) and then farmers (22\%). Those who worked hard physically are affected comparatively less, but comparatively more farmers are affected in this study possibly due to the lack of follow up and pre evaluation of risk factors.

In this study it is obvious that hypertension is the most common risk factor (76\%) In another study in BIRDEM by Latif et. $\mathrm{al}^{8}, 50-30 \%$ with NIDDM and stroke were also hypertensive. In a multi-factorial analysis of risk factors of ischemic strokes, the association of hypertension was found in more than $60 \%$ patients ${ }^{9}$. So all these national and international studies agreed that there is a strong association between hypertension and ischemic stroke. Majority of the patients of this study population (84\%) were previously known hypertensive. Newly daignosed case were only (16\%). Among the diagnosed group most (62\%) were taking antihypertensive medication 
irregularly. This implies the lack of awareness of the hypertension and its dreadful consequences causing significance morbidity and mortality. So, prevention, detection and proper management of hypertension alone can bring down the incidence of stroke $^{10}$.

In this study $38 \%$ of stroke patients were found to be smoker, duration of smoking varied among the study group. In two separate studies, Yano Donovan have shown strong association between smoking and stroke ${ }^{11}$. Macfarlane et. $\mathrm{al}^{12}$, had concluded that combination of raised systolic blood pressure and cigarette smoking resulted in a more then 10 fold increase risk of developing stroke compared with that in normotensive and non smoker. In this study there is also a significant association of smoking with stroke.

In this study (16\%) of the stroke patients were found to be diabetes mellitus among which $54 \%$ patients were getting regular treatment, $34 \%$ were getting irregular treatment and $12 \%$ were detected $1^{\text {st }}$ time after admission. All the diabetic patients were type 11. Another study ${ }^{13}$ has shown that 10 to 14 percent of stroke patients were diabetic. The Copenhagen stroke study showed $20 \%$ stroke patient has diabetes mellitus and diabetes influenced stroke in several aspects including age, subtypes and treatment. In a study at BIRDEM ${ }^{8}$ on 165 cases of diabetic patients with stroke showed, majority of them developed stroke in less than 10 years duration of diabetic. As there is a link between diabetes mellitus, hypertension and hyperlipidaemia it is difficult to asses its predominant role on stroke. However, when all these conditions are present in a patient, the relative risk of suffering from stroke is greater ${ }^{13}$. But unfortunately there is no convincing evidence that metabolic control of diabetes mellitus reduce the risk of stroke.

Among the study group (12\%) were hyperlipidaemic. We know atherosclerosis play an important role in the pathogenesis of stroke, Shuaib et.al. ${ }^{14}$ concluded that progressive carotid atherosclerosis, cardiac arrhythmia and embolic vascular changes all contribute to the increase incidence of stroke particularly in the elderly.
In this study the WHR shows that $64 \%$ patients had abnormal ( $>1$ in men and $>0.85$ in women) WHR, while only (36\%) patients had been found to have this within normal limit and there were no comparable data for Bangladeshi people found for an evaluation.

This study show a significant but not independent association between ischemic stroke and an elevated WHR. Vague first suggested that atherosclerotic risk was higher in those with abdominal obesity compared with lower body obesity. Other investigators also have reported that abdominal fat distribution is highly related to an increased prevalence of cardiovascular risk factors ${ }^{15}$. The measurement of waist circumference alone is a simple indicator of abdominal obesity but has not been found to be a good predictor of stroke in this and other studies ${ }^{16}$. The effect of WHR was apparent after controlling for BMI. In fact, BMI had a slight inverse association with ischemic stroke ${ }^{17}$. In some studies, current smoking, heavy alcohol drinking may lead to reduced BMI and an increase in the risk of stroke and therefore confound the association between BMI \& stroke ${ }^{17}$ Moreover, weight or BMI can decrease with age because of a loss of lean body mass and a measurement of WHR may be a more useful method to assess abdominal fat accumulation and a better predictor of an increased risk for stroke then BMI or waist circumference ${ }^{18}$.

In some cohort studies, WHR was no longer risk factor for stroke after adjustment for hypertension and blood lipids or diabetes but the number of events in these studies was small. These studies also failed to differentiate between infarction and hemorrhage as separate outcome ${ }^{16,18}$

This study also reveals that abdominal obesity as defined by waist to hip ratio (WHR) is also strongly linked to ischemic stroke but several limitation of this study design deserve discussion. The population based approaches of this study, however and the matching by age, sex and race-ethnicity help to minimize the potential biases.

Our anthropometric measurement were performed after the stroke and may not accurately reflect the premorbid status of obesity because waist and hip circumference could be changed by inadequate nutritional intake after acute stroke. Measurement 
error may also have occurred because WHR was measured in the supine position in some cases who were unable to stand. In a pilot study waist circumference measured when supine were slightly smaller than when measured standing, whereas hip circumferences did not differ by position measured.

However, the current study was conducted on a small group of patients (50 cases) and its result shows an association with ischemic stroke. This association may be evaluated further through conduction of similar study on larger scale considering above mentioned limitations.

\section{References:}

1. National Center for Health Statistics. Prevalence of overweight and obesity among adults: United States, 1999. Available at: http:/ /wvw.cdc.gov/nchs/products/pubs/pubd/ hestats/obese/ obse99table 2.htm. Accessed December 6, 2008.

2. Must A, Spadano J, Coakley EH, Field AE, Colditz G, Dietz WH. The disease burden associated with overweight and obesity. JAMA. 1999; 282: 1523-9.

3. Schule H, Cullen P, Assmann G. Obesity, mortality and cardiovascular diseases in the Munster Heart Study (PROCAM). Atherosclerosis. 1999; 144: 199- 209.

4. Lapidus L, Bengtsson C, Larsson B, Pennert K, Rybo E, Sjostrom L. distribution of adipose tissue and risk of cardiovascular disease and deatth: a 12 year follow up of participants in the population study of women in Gothenburg, Sweden. BMJ. 1984; 289: 1257-61.

5. Lindenstrom E, Boyesen G, Nyboe J. Lifestyle factors and the risk of cerebrovascular disease in women: the Compenhagen City Stroke Study. Stroke. 1993; 24: 1468-72.

6. Chowdhury SGM, Ahmed Q, Dhan FD, Alam MR, Arif SM, Roy PK. Stroke in patients having inadequate or irregular antihypertensive therapy. Bangladesh Med Res Coun Bull 1990; XVI: 52-7.

7. Alamgir SM, Mannan MA. Cerebrovascular disease (A report of 53 cases). Bangladesh Med Res Coun Bull 1975; 1: 45-50.
8. Latif ZA, Zaman SM, Ahad A, Rahim SA. Study of stoke between normotensive and hypertensive NIDDM cases in BIRDEM, Dhaka, Bangladesh, J. Neurosci. 1990; 6: 52-6.

9. Robert et al."Effect of thiazolidinediones on body weight in patients with diabetes mellitus". Am. J. Med. 115 Suppl 8A: 42S-48S.

10. Rahman HJ, Mannan MA, Haque A. Prognosis of acute stroke. Bangladesh J Neurosci. 1987; 3: 42-7.

11. Yano K, Reed DM, Yin Y, Abbott RD. Risk of stroke in male cigarette smokers. N? Engl. J. Med. 1986; 315: 717-20.

12. Macfarlance PW, Walker M, Pocker SJ, Phillips AN, Shaper AG. Risk factors for stroke in Middle aged british men. Br Med J 1991; $1111-5$.

13. Thompson SBn, Morgan M, editors. Epidemiology of stroked. In: Occupational Therapy for stroke rehabilitation, $1^{\text {st }}$ ed. London: Chapman and Hall, 1990: 1-14.

14. Leppala JM, Virtamo J, Fogelholm R, Albanes $D$ and Heinoren OP (1999). Different risk factors for different stroke subtypes: association of blood pressure, cholesterol, and antioxidants. Stroke, 30: 2535-40.

15. Goldstein LB, Adams R, Becker K, Furberg CD, Gorelick PB, Hademones G, et al. AHA Scientific Statement: primary prevention stroke: a statement for healthcare professionals from the Stroke Council of the American Heart Association. Stroke. 2001; 32: 280-99.

16. Abott RD, Behrens GR, Sharp DS, Rodriguez $\mathrm{BL}$, Burchifiel CM, Ross et al. Body mass index and thromboembolic stroke in nonsmoking men in older middle age: the Honolulu Heart Program. Stroke. 1994; 25: 2370-6.

17. Calle EE, Thun MJ, Petrelli JM, Rodriguez C, Heath CW Jr. Body-mass index and mortality in a prospective cohort of U.S. adults. NEngl J Med. 1999; 341: 1097-1105.

18. Lapidus L, Bengtsson C, Larsson B, Pennert $K$, Rybo E, Sjostrom L. distribution of adipose tissue and risk of cardiovascular disease and deatth: a 12 year follow up of participants in the population study of women in Gothenburg, Sweden. BMJ. 1984; 289: 1257-61. 